\title{
Exploring the awareness of health and life promotion from the differences in the lifestyles of young people before and during the epidemic
}

\author{
Sheng-Ming Wang ${ }^{1}$ \\ Department of Interaction Design, National Taipei University of Technology, Taiwan \\ E-mail: ryan58850mail.ntut. edu.tw
}

\section{Wei-Jie Pan}

Department of Interaction Design, National Taipei University of Technology, Taiwan

E-mail: xiaopanzizi@gmail.com

\begin{abstract}
During the outbreak of the Covid-19 epidemic, many countries took strict measures of prevention, including city lockdowns, production, school shutdowns, and home quarantine, to prevent further spread of the pandemic. Relevant actions have affected people's daily routines and life patterns, even changed the original lifestyle. Especially for youngsters, their diversified lifestyle is significantly impacted. Related studies show that abnormal changes in daily life patterns or bad habits change the lifestyle and lead to the emergence of a sub-health state. Therefore, the primary purposes of this study are 1. to investigate the differences in lifestyle among young generation before and during the epidemic; 2. to further analyze the changes and the factors that may affect their health. in order to increase people's interest in the research and enhance the participation of young generation, this study introduces the method of "Life Stripe Project" established by Japanese designers. Based on this model, the questionnaire of daily life patterns was derived online, where data of daily life activities of college students in Taiwan and mainland China were collected through an online survey. At the same time, six factors of health-promoting lifestyle theory have been introduced to analyze the factors affecting the lifestyle change before and during the epidemic, and to find out the reasons resulting in the sub-health state, to guide the young generation to deal with the possible continuation of the epidemic situation. Proper adjustment and plans for their daily life activities will help to enhance their awareness of health-promoting life in the future.
\end{abstract}

Keyword: Covid-19 Epidemic, Lifestyles, Health-promotion Life-Stripe, Differentiate-analysis, Suboptimal Health Status 


\section{Introduction}

Many countries have adopted prevention measures suitable for their national status facing the break out of the epidemic. At least one-third of the global population has taken home quarantine during the epidemic period to prevent further spread. Related papers released by "The Lancet Psychiatry" have pointed out that there are eight vulnerable groups, among which the group of younger age (college students) is one of the most affected groups. Most of the students studied in schools before the epidemic, but in order to reduce the risk of personnel mobility and cross infection, they had to stay at home, and the learning places were changed from campus to home. The change of living environment leads to the change of daily life activities. The abnormal change of life pattern and the influence of negative information of epidemic situation would quickly lead to the sub-health state. Therefore, this research starts by studying the changes in daily life activities under the influence of epidemic situations. Through the analysis of 21 Activities and their corresponding colors of the Life-strip Project established by a Japanese couple, designers Haruna Yamada and Hirokazu Kobayashi, the web page version questionnaire of daily life activities is derived. Since Taiwan is less affected by the epidemic, home quarantine was not mandated, whereas for mainland China the outbreak was severe, and home quarantine policy was strictly implemented. Therefore, the difference of impact to different regions brought differences in the activities of university students. In this case, information on daily life activities of 114 college students from Taiwan and mainland China before and during the epidemic were collected online by this questionnaire. These data will be used to analyze the different time patterns and lifestyles through SPSS software and prepare for further comparison of different lifestyles.

Meanwhile, six factors in the theory of health-promoting lifestyle are integrated, including sports and leisure, nutrition, stress treatment, human-computer relationship, health responsibility, and spiritual growth. Twenty-one activities defined in the Life-stripe Project are classified and integrated to analyze the changes of life style among the young generation before and during the epidemic to find out about the possible factors that may result in the sub-health state as well as the extent and orders of these factors. It is expected to better understand the issues that the young generation might encounter during the epidemic and guide them in the continuous situation. Proper adjustment and plans for daily life activities will improve their awareness of healthpromoting lifestyle and reduce the emergence of sub-health states.

\section{Literature Review}

\subsection{Third state of human health (sub-health / grey state)}

The third state refers to the marginal state between health and illness, also known as "suboptimal health status / SHS". The World Health Organization (WHO) points out that being healthy is a perfect state of body and spirit, not just a disease-free state. According to this definition, the organization has made rigorous statistics and concluded that the proportion of the real healthy people (the first state) and people with the disease (the second state) take less than $1 / 3$ of the total population, while over $2 / 3$ of the population are in the transitional state between health and illness, which is referred to as "the third state" by WHO, also known as "sub-health state" and "gray state" [1]. There was a significant positive correlation between health status and lifestyle. Poor lifestyle is a risk factor for the third state. 
On the contrary, a healthier lifestyle can improve the third state [2]. The third state is the major global public health challenge. Those who are in the third state cannot reach the established standard, which is manifested by the decrease of vitality, various malfunctions, and inadaptability in a certain period. Although the underlying reason is still unclear, lifestyle is one of the most important factors affecting health status [3]. Many lifestyles affect a person's ability to maintain energy balance in the long run. For example, the duration of sleep can affect energy consumption. An unhealthy lifestyle is also closely related to many chronic diseases. As shown in relevant reports, the main risk factors of poor health generally include poor stress management, poor selfrealization ability, lack of physical exercise, and poor interpersonal relationship [4].

\subsection{Third state of human health (sub-health / grey state)}

The outbreak of Covid-19 has put the public in a high-stress state in physiological, psychological, and social conditions, and has brought challenges global wise to the changing of people's lifestyle, thus induces adverse health [5]. Words such as "social alienation" and "selfisolation" are often used among people. People are trying to adjust while the conditions like home quarantine has greatly affected people's lives and has brought sudden and fundamental changes to their daily lives [6]. The critical function of a healthy lifestyle (HLS) is highly recognized in reducing all-cause mortality as well as maintaining individual health and well-being [7]. A healthy lifestyle contains many behaviors, where health-promoting behavior is the critical element of a healthy lifestyle. The health-promoting behavior of an individual is regarded as a positive lifestyle, which leads him to recognize his health potential. Generally speaking, a healthpromoting lifestyle integrates a comprehensive and diversified interpersonal environment both for physiology and psychology.[8].

Health-promoting lifestyle plays a vital role in the transformation of the third state [9]. The third state (SHS) refers to a poor state of physical and mental health between being healthy and being ill, which is mainly manifested in the changes of three aspects, namely, psychology, body, and social adaptation [10]. The third state has the characteristics of bidirectional transformation, which can develop into a disease state and reverse into a health state. However, based on the health-promoting lifestyle, identifying the combined risk factors of lifestyle and early intervention can promote the reversal of the third state to the healthy state, thus reduce the transition to the disease state. Therefore, preventing and intervening in lifestyle risk factors is an important way to improve the third state health condition and return to a healthy state [11]. Combined with the six factors of health-promoting lifestyle, results show that the influencing factors of healthpromoting lifestyle of college students' health status transformation at school are respectively: mental growth, health responsibility, interpersonal relationship, stress management, nutrition, and sports leisure [12].

The explanation of these six factors are as follows: Nutrition: which involves daily diet pattern, food choice, mealtime and habits, etc. Interpersonal relationship: such as the support system to develop social relationships, close interpersonal relationship, or being active in discussing personal problems with others, spending time with close friends, etc. Stress management: which includes the ability to relax themselves and relieve pressure, progressive relaxation techniques, meditation, proper rest, and adequate sleep - these activities can make the organ system stable and conducive. Sports and Leisure: refers to whether to engage in sports and leisure activities on weekdays, for instance, at least three times a week, 30-40 minutes each time. 
Health responsibility: which means taking the responsibility of self-protection, learning to take care of ourselves to maintain individual health and prevent disease and restore health. It also includes paying attention to one's own health, discussing health care-related issues with professionals, etc. Spiritual growth includes purposeful life to strive towards goals, being optimistic about life, and having a positive sense of growth and change [13].

\subsection{Health awareness and health behavior}

For the young generation of the modern time, health issues are somewhat influenced by psychology and behavior than traditional infectious diseases or general physiological diseases. Many studies have pointed out that health behavior has a significant impact on the overall health status of individuals [6]. Many factors may influence an individual's health behavior, one of which is health awareness. An individual's subjective cognition of health will influence their attitude and behavior towards life. Relevant studies show that correct concept or consciousness of health can promote healthy behaviors, which means the earlier to develop personal health cognition and behavior, the more conducive to the development of health maintenance and sustainability. If the correct concept of the importance of individual health can be given at an early stage, it will result in the practice and motivation of healthy behavior in the future [14]. The "Health Belief Model" formed by people's awareness of health will affect the practice of their health behaviors. In this model, the main factors that affect people's specific health behaviors are the individual's perception of health threats and the perception that certain health methods can effectively reduce health threats. Empirical research on health behavior relating to health awareness shows that college students with higher scores of health awareness also have higher scores of diet behavior and lifestyle of health promotion [15]. College Students' healthy behavior will also affect their mental health. Students who are willing to change their health behaviors will have lower risk of depression. The willingness to change their health behaviors indicates that college students' health awareness has improved, and positive action is conducive to mental health. Therefore, a healthy lifestyle should be greatly advocated [16].

\subsection{Life Stripe Project}

Life Stripe is a documentary type of art project with experimental nature. It is a project that has been carried out since 2004 by a studio named Spread, founded by a Japanese couple, designers Haruna Yamada and Hirokazu Kobayashi. This project believes that life can create beautiful patterns, while reflecting on the past helps create the future. The project studies people's different lifestyles through the distribution of color. Over the years, more than 150000 cases of related data have been collected from different age and gender groups with different occupational and living backgrounds.

Meanwhile, the data of animals were recorded in the same way. At first, the designer composed a questionnaire of behavior and color definition through statistics and eventually determined 21 kinds of activities corresponding to 21 colors. Then, the time length of each activity are expressed by the stripes of different thickness and detail to show the time distribution of all behaviors in a day (Fig. 1). 
Figure 1: Life Stripe Project Content

\section{Research Process and Method}

The following is the research process (as shown in Figure 2)

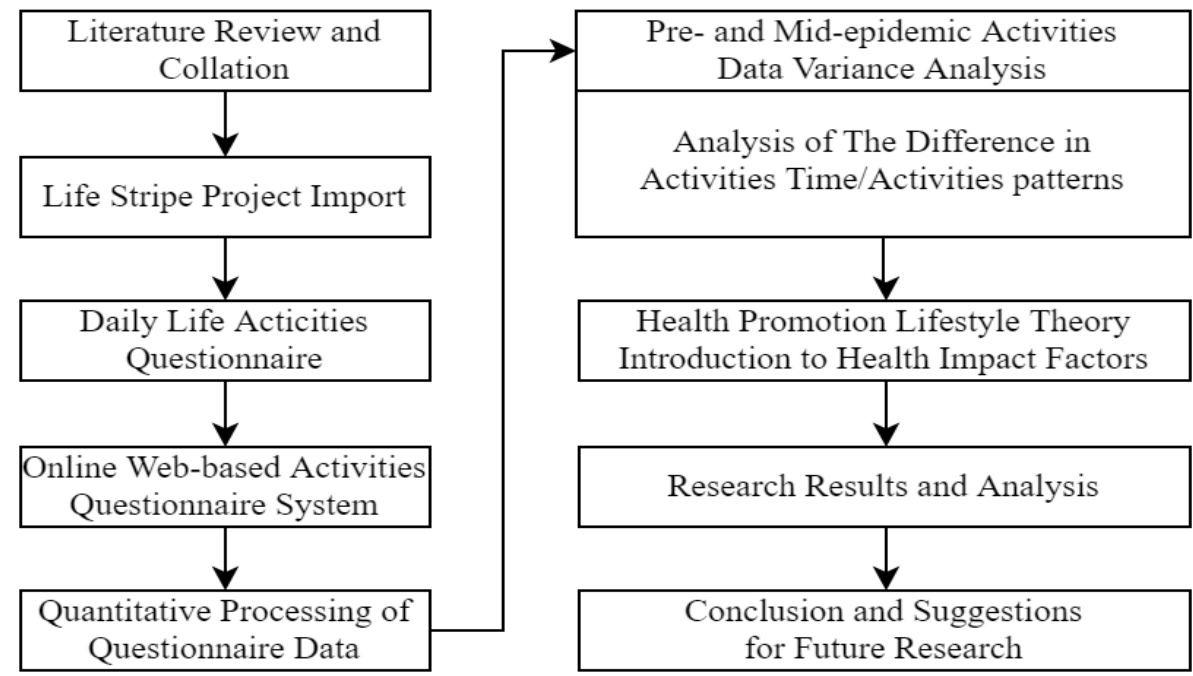

Figure 2: Research Flow Chart

This study will collect information on the young generation's daily life activities before and during the epidemic. In order to increase the interest of participation among college students, the 21 daily life activities and their corresponding into six steps (as shown in Figure 3/4), namely, entering the online questionnaire collection home page; going through the description of filling out; going through the introduction of Life Stripe Project; going through the method of filling out; starting to fill our your personal colors; and filling out personal information. The target respondents are mainly college students in mainland China and Taiwan, aged from 19 to 31 . The information to be collected are daily life activities as well as personal information before and during the epidemic.
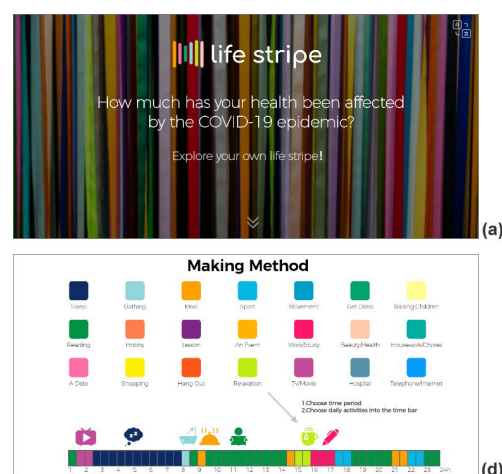
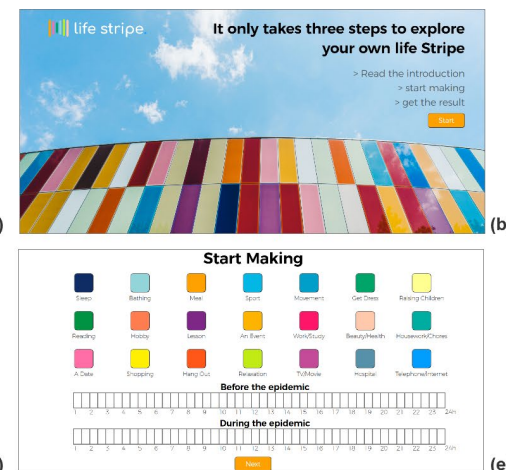

(e)

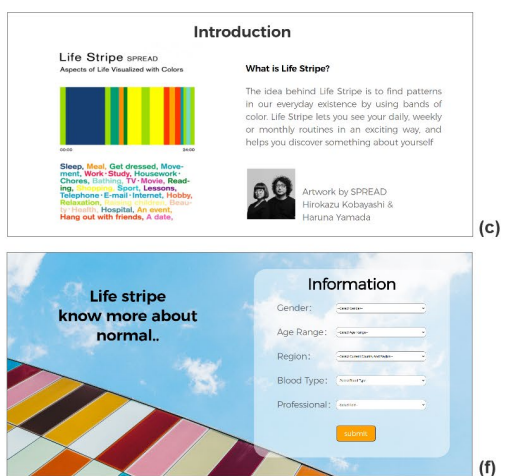

Figure 3: Web Design of Collection Survey 


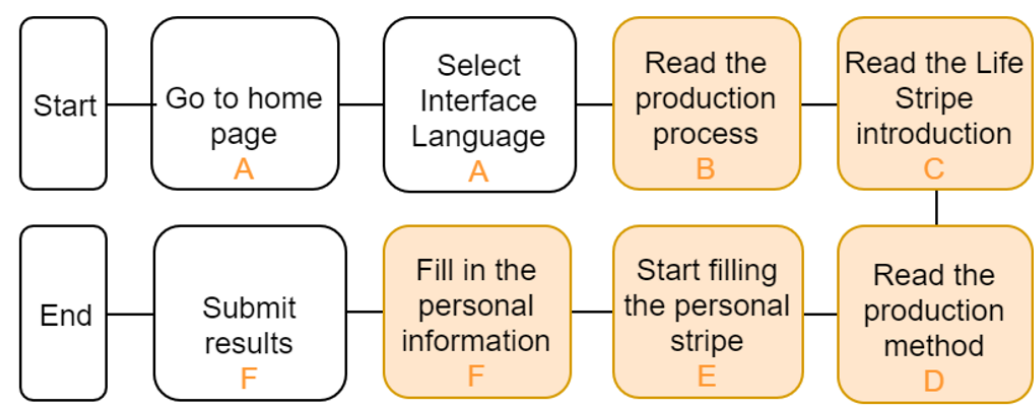

Figure 4: Online Questionnaire Collection Process

In order to analyze the factors that may change daily life activities and may finally lead to the third state, the six factors of health-promoting lifestyle theory were introduced. Twenty-one daily life activities in the Life Stipe Project were summarized into the corresponding factors. After analyzing the six factors from the relevant literature, this paper preliminarily classifies the meal schedule in the Life Stripe into the nutrition factor. Simultaneously, due to the widespread of meal schedule, which is not conducive to the follow-up analysis, it is further divided into breakfast, lunch, and dinner. Sports and hobbies are classified as exercise leisure factors. Overall sleep, watching movies and TV, strolling, and relaxation are classified into the stress management factors, among which the overall sleep schedule is divided into noon and evening sleep schedule. Phone calls, e-mails, dating, and child care are classified as interpersonal relationship factors. Housework, beauty care, hospital, and bath are classified as health responsibility factors; Work, study, reading, curriculum, grooming, commuting, and shopping are classified as spiritual growth factors (see Figure 5 below).
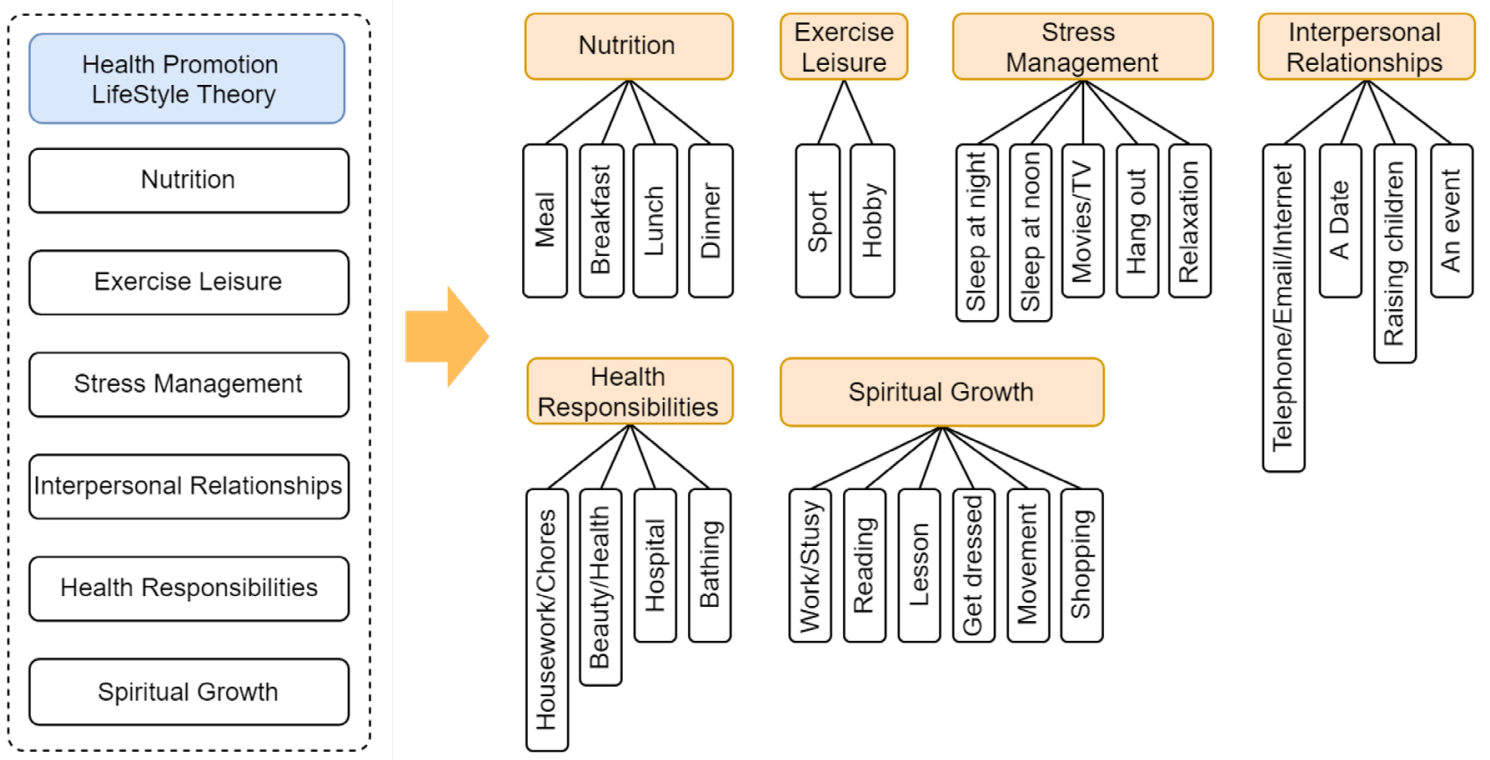

Figure 5: The relationship between health promotion lifestyle theory and 21 activities

The data collected by the questionnaire was accessed with SPSS software to calculate the average time spent in daily life activities with the proportion of people both before and during the epidemic to analyze the differences. Through the cluster analysis function of SPSS, differences in daily life patterns between before and during could also be analyzed. The result of analysis on different life patterns were presented with color stripes so that readers can understand the changes that took place before and during the epidemic more intuitively. Finally, the six factors in the 
health-promoting lifestyle theory were adopted to explore the factors that may affect the emergence of the third state among the young generation.

\section{Data Collecting, Analysis, and Discussions}

\subsection{Data collecting and overall analysis}

This study has completed the design and construction of the Life Stripe online questionnaire and has collected 114 samples from the college students in Taiwan and mainland China for both before and during the epidemic, including 57 in China and 57 in Taiwan. All of the data was accessed by SPSS to filter the unreasonable ones, then calculate respectively the average time spent on daily life activities and the proportion of the number of people engaged in the two regions. The results were classified according to the six factors mentioned above in the healthpromoting lifestyle theory 6(as shown in Table 1). The life stripes filled in by the subjects were also derived from the online questionnaire, which was classified according to the different periods and gender (as shown in Figure 6: left - before the epidemic / right - during the epidemic; upper female / lower-male). Colored blocks showing the same daily life activities are displayed separately through conditional screening (as shown in Fig. 7). Simultaneously, the cluster analysis results of SPSS were presented in the form of colored stripes (as shown in Figure 7: S1 / S2) to analyze the differences of the same daily life activities patterns from the visual presentation. With the calculation result from SPSS access and through observation of the differences presented by Life Stripe, it is concluded that there are apparent differences in daily life activities between before and during the epidemic, which are shown as follows: eating breakfast, sports, hobbies, sleeping at noontime, watching movies and TV, phone calls and e-mails, activities, housework, beauty care, work and study, reading, learning courses and commuting.

Table 1: Comparison of activity data in China and Taiwan before and after the epidemic

\begin{tabular}{|c|c|c|c|c|c|c|c|c|c|}
\hline \multirow[b]{2}{*}{$\begin{array}{l}\text { Health } \\
\text { Promotion } \\
\text { LifeStyle } \\
\text { Theory }\end{array}$} & \multirow[b]{2}{*}{$\begin{array}{l}\text { Daily Life } \\
\text { Program }\end{array}$} & \multicolumn{4}{|c|}{ Time $(H)$} & \multicolumn{4}{|c|}{ Percentage of people with that routine (\%) } \\
\hline & & $\begin{array}{c}\text { Pre- } \\
\text { epidemic } \\
\text { China }\end{array}$ & $\begin{array}{l}\text { During- } \\
\text { epidemic } \\
\text { China }\end{array}$ & $\begin{array}{c}\text { Pre- } \\
\text { epidemic } \\
\text { Taiwan }\end{array}$ & $\begin{array}{l}\text { During- } \\
\text { epidemic } \\
\text { Taiwan }\end{array}$ & $\begin{array}{c}\text { Pre- } \\
\text { epidemic } \\
\text { China }\end{array}$ & $\begin{array}{l}\text { During- } \\
\text { epidemic } \\
\text { China }\end{array}$ & $\begin{array}{c}\text { Pre- } \\
\text { epidemic } \\
\text { Taiwan }\end{array}$ & $\begin{array}{l}\text { During- } \\
\text { epidemic } \\
\text { Taiwan }\end{array}$ \\
\hline \multirow{3}{*}{ Nutrition } & Breakfast & 0.3 & 0.4 & 0.2 & 0.2 & 59.6 & 50.9 & 35.1 & 19.3 \\
\hline & Lunch & 0.7 & 0.9 & 0.8 & 0.9 & 96.5 & 93.0 & 78.9 & 82.5 \\
\hline & Dinner & 0.7 & 0.8 & 0.6 & 0.8 & 89.5 & 87.7 & 63.2 & 77.2 \\
\hline \multirow{2}{*}{$\begin{array}{c}\text { Exercise } \\
\text { Leisure }\end{array}$} & Sport & 0.3 & 0.3 & 0.2 & 0.3 & 24.6 & 21.1 & 15.8 & 19.3 \\
\hline & Hobby & 0.5 & 0.5 & 0.2 & 0.5 & 29.8 & 24.6 & 10.5 & 22.8 \\
\hline \multirow{5}{*}{$\begin{array}{c}\text { Stress } \\
\text { Management }\end{array}$} & Sleep at night & 7.8 & 8.5 & 7.4 & 8.6 & 98.2 & 98.2 & 98.2 & 93.0 \\
\hline & Sleep at noon & 0.7 & 0.5 & 0.1 & 0.1 & 68.4 & 38.6 & 5.3 & 8.8 \\
\hline & Movies/TV & 0.7 & 2.1 & 0.7 & 1.7 & 38.6 & 63.2 & 28.1 & 52.6 \\
\hline & Hang out & 0.1 & 0.0 & 0.1 & 0.2 & 5.3 & 0.0 & 10.5 & 12.3 \\
\hline & Relaxation & 1.7 & 2.6 & 1.8 & 3.1 & 71.9 & 77.2 & 73.7 & 71.9 \\
\hline \multirow{4}{*}{$\begin{array}{l}\text { Interpersonal } \\
\text { Relationships }\end{array}$} & Telephone/Email/Internet & 0.8 & 1.2 & 1.0 & 1.9 & 36.8 & 42.1 & 50.9 & 56.1 \\
\hline & A Date & 0.1 & 0.0 & 0.2 & 0.3 & 3.5 & 1.8 & 7.0 & 8.8 \\
\hline & Raising children & 0.0 & 0.1 & 0.0 & 0.0 & 0.0 & 5.3 & 0.0 & 0.0 \\
\hline & An event & 0.2 & 0.4 & 0.0 & 0.2 & 14.0 & 17.5 & 1.8 & 5.3 \\
\hline \multirow{4}{*}{$\begin{array}{c}\text { Health } \\
\text { Responsibilitie } \\
\text { s }\end{array}$} & Housework/Chores & 0.1 & 0.6 & 0.1 & 0.3 & 7.0 & 31.6 & 8.8 & 19.3 \\
\hline & Beauty/Health & 0.1 & 0.2 & 0.1 & 0.1 & 14.0 & 17.5 & 12.3 & 14.0 \\
\hline & Hospital & 0.0 & 0.0 & 0.0 & 0.0 & 0.0 & 0.0 & 0.0 & 0.0 \\
\hline & Bathing & 0.6 & 0.5 & 0.8 & 0.8 & 82.5 & 68.4 & 73.7 & 91.2 \\
\hline \multirow{6}{*}{$\begin{array}{l}\text { Spiritual } \\
\text { Growth }\end{array}$} & Work/Stusy & 5.8 & 3.1 & 4.8 & 3.1 & 86.0 & 61.4 & 77.2 & 45.6 \\
\hline & Reading & 0.4 & 0.5 & 0.5 & 0.3 & 29.8 & 33.3 & 24.6 & 12.3 \\
\hline & Lesson & 1.7 & 0.3 & 3.3 & 0.1 & 29.8 & 5.3 & 59.6 & 7.0 \\
\hline & Get dressed & 0.3 & 0.2 & 0.4 & 0.3 & 47.4 & 33.3 & 49.1 & 31.6 \\
\hline & Movement & 0.3 & 0.3 & 0.5 & 0.2 & 24.6 & 21.1 & 40.4 & 22.8 \\
\hline & Shopping & 0.0 & 0.0 & 0.1 & 0.1 & 3.5 & 1.8 & 7.0 & 7.0 \\
\hline
\end{tabular}



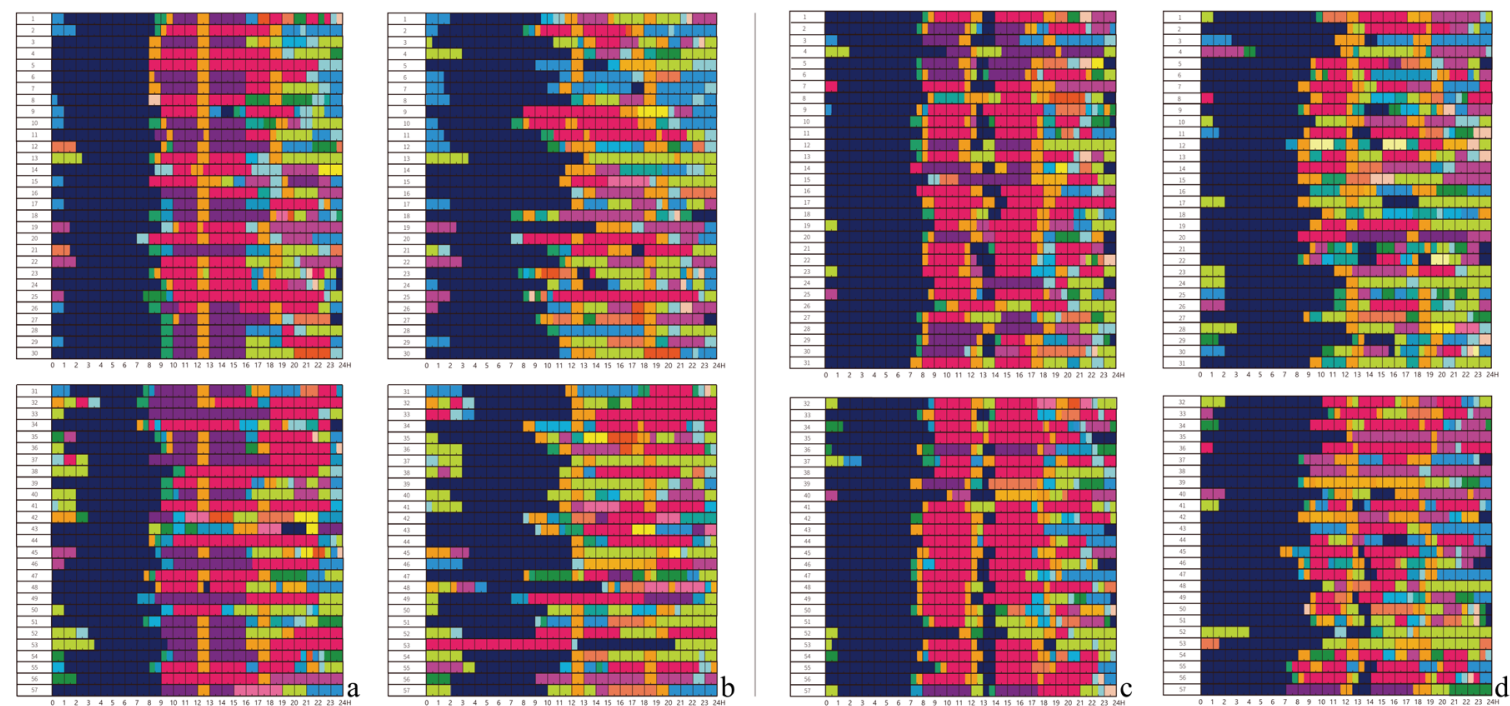

Figure 6: Visual representation of life stripe $(\mathrm{a} / \mathrm{b})$ Taiwan region; $(\mathrm{c} / \mathrm{d})$ China region.

Based on the six factors, concrete analyses on the significant differences between before and during the epidemic were carried out.

\subsection{Data collecting and overall analysis}

\subsubsection{Nutrition factor analysis (as shown in Fig.7)}
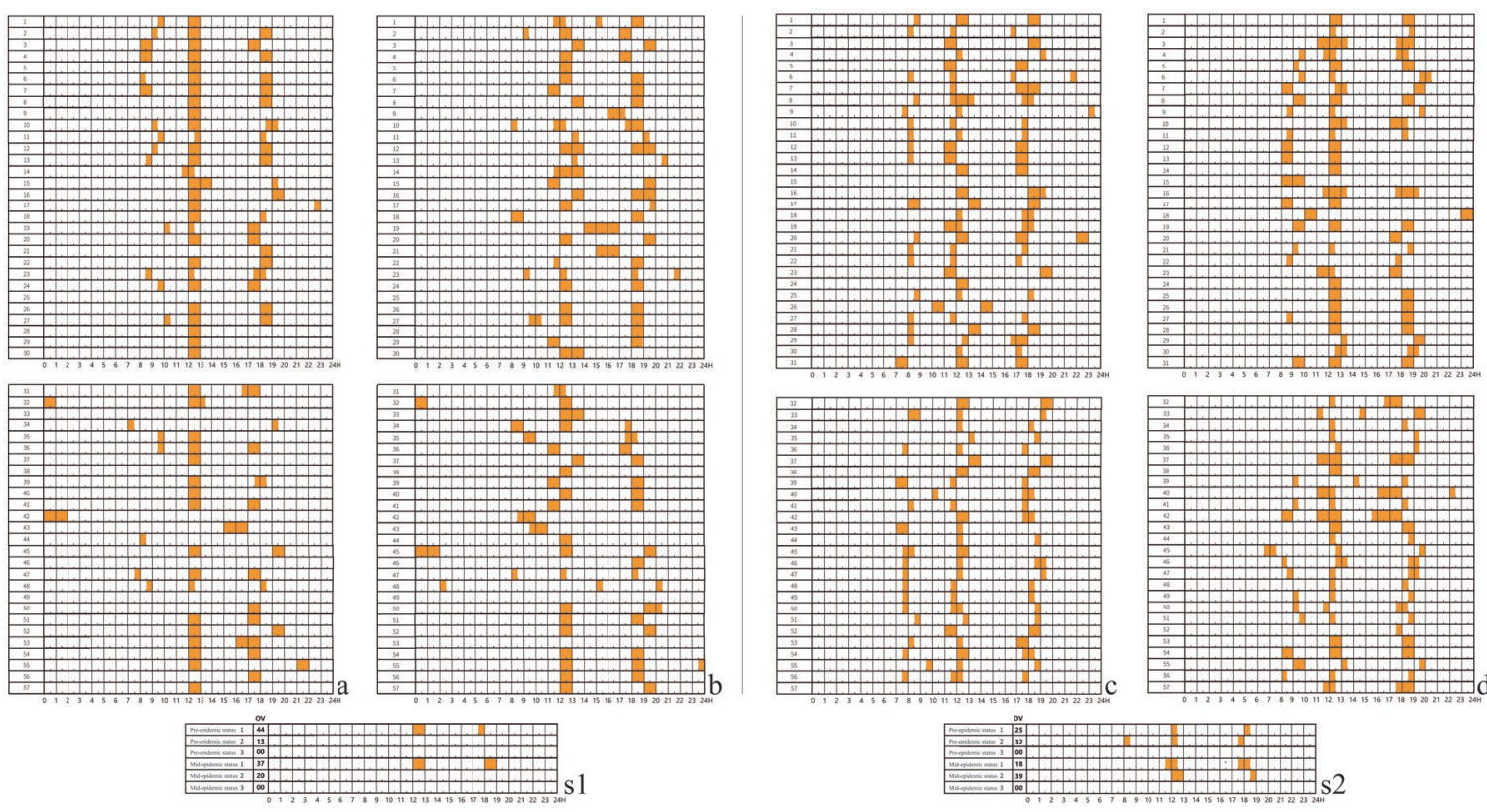

Figure: 7 Meal (a/b) Taiwan region; (c/d) China region.

In Taiwan: No matter before or during the epidemic, the number of people who eat breakfast is less than half. The number has decreased significantly during the epidemic, and the average time spent on lunch and dinner increased slightly.

In mainland China: Before the epidemic, more than half of the students took breakfast, while the number during the epidemic decreased by $10.7 \%$ compared with that of before. Combined with sleep activities, it can be concluded that the number of students taking breakfast decreased because the time of getting up was close to lunchtime. The average time spent on lunch and dinner during the epidemic was higher than that of before. 
Analysis results: irregular meal patterns (breakfast) during the epidemic is a factor that may result in the third state. For both regions during the epidemic, the number of people regularly eating breakfast decreased, mainly because they got up late in the morning, at the close to lunchtime, so more people skipped breakfast. There was no significant change for lunch and dinner, but only the average time spent increased slightly. According to relevant studies in the United States, researchers conducted an 18-year follow-up study on 6550 participants who participated in the national health and nutrition survey. The results showed that taking into account age, gender, diet, lifestyle, and other factors, the risk of cardiovascular death increased by $87 \%$, and all-cause death increased by $19 \%$ in those who did not eat breakfast comparing to those who ate breakfast regularly and the risk stroke increased by $239 \%$.

\subsubsection{Exercise and leisure factor analysis (Fig.8/Fig.9)}
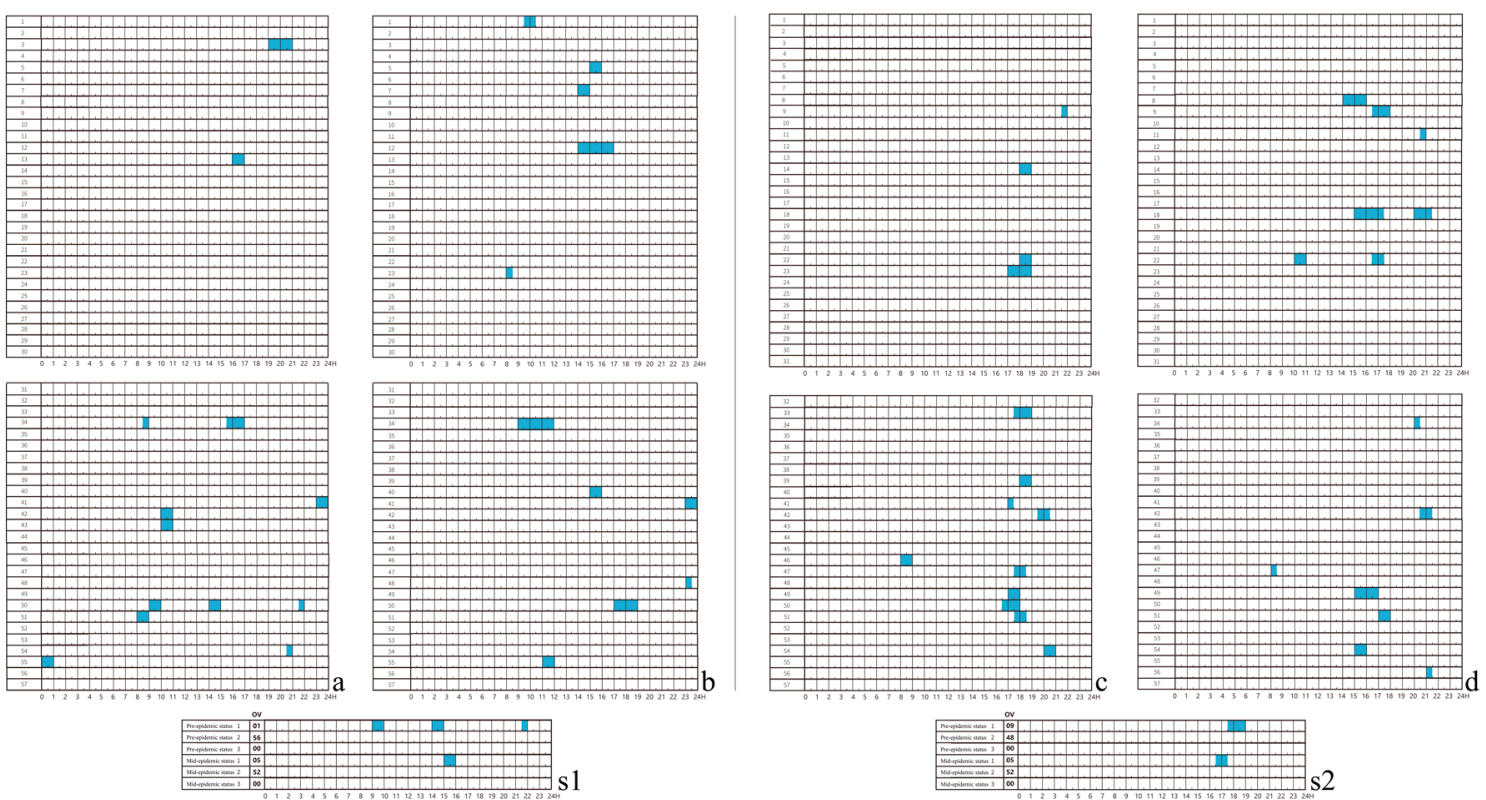

Figure 8: Sports (a/b) Taiwan region; (c/d) China region
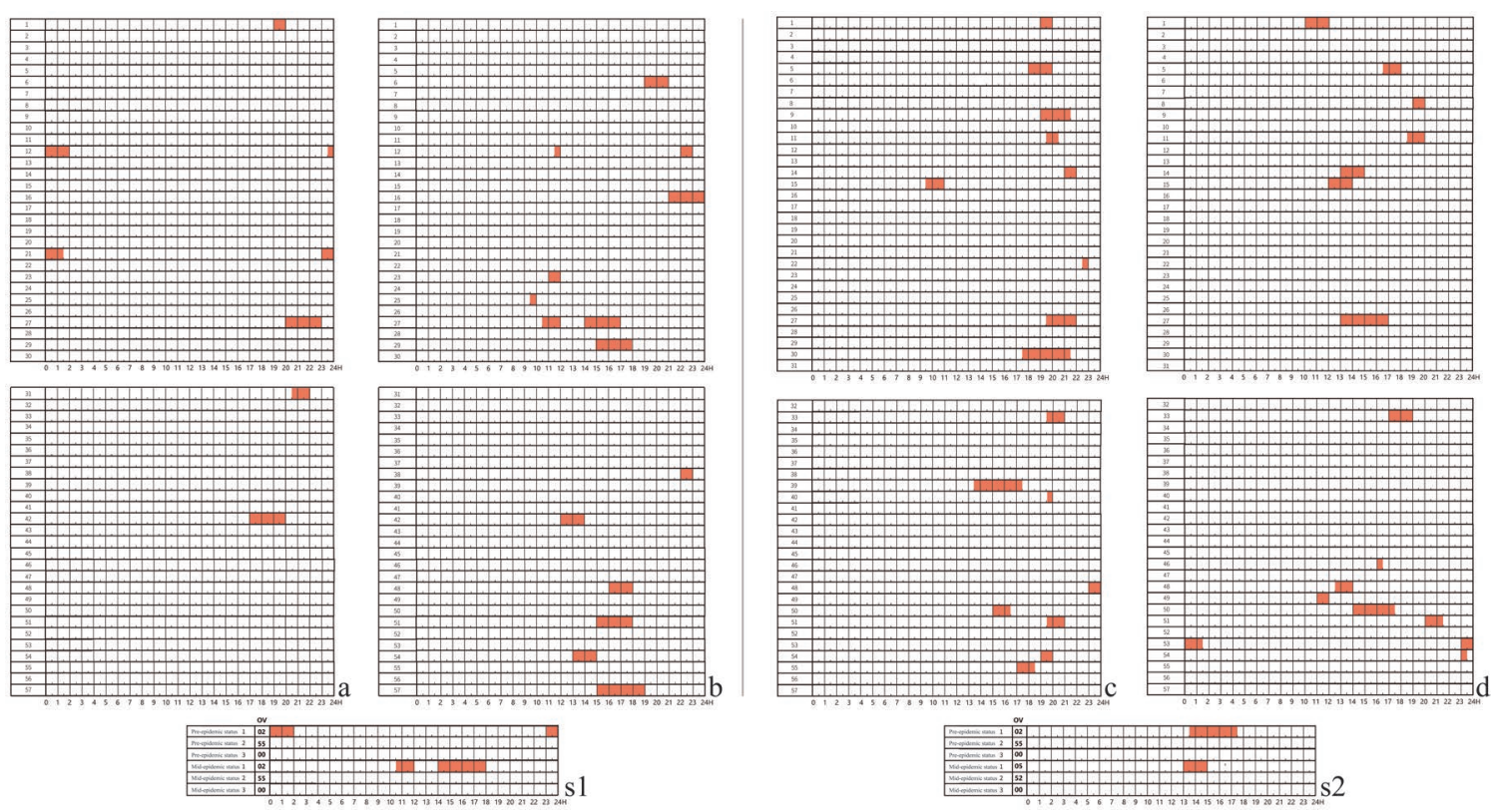

Figure 9: hobbies ( $a / b)$ Taiwan region; (b/d) China region 
In Taiwan, the number of people who did physical exercise before the epidemic was less, and the average time spent was also low; but the average time and number of people who did exercise increased during the epidemic. The number of people increased by $12.3 \%$.

In mainland China: before and during the epidemic, the average time spent on exercise was low. The number of people who took exercise during the epidemic decreased even further (down by $5.5 \%$ ); activities initiated by hobby showed a downward trend affected by the epidemic.

Results analysis: Lack of awareness and habit of physical exercise during the epidemic is a factor that may cause the third state. In mainland China, where the epidemic situation was difficult, sports activities were shown with a downward trend; while in Taiwan, where the epidemic situation is relatively mild, an upward trend was developed. The reason may be that although the epidemic situation in Taiwan was mild, there still existed the risk of being affected, and the health awareness of students were improved, thus the increase. In the epidemic situation, the awareness of sports should be paid more attention. Although many sports cannot be carried out in a home quarantine situation, indoor activities could be alternatives so as to enhance physical power. The definition of hobbies is relatively broad, such as painting, photography, listening to music, drinking, playing games, etc. The influence of sports and leisure factors can be divided into positive and negative, and follow-up interviews will be conducted to understand more about specific hobbies for a more detailed analysis.

\subsubsection{Stress management factor (Fig.10/Fig.11)}
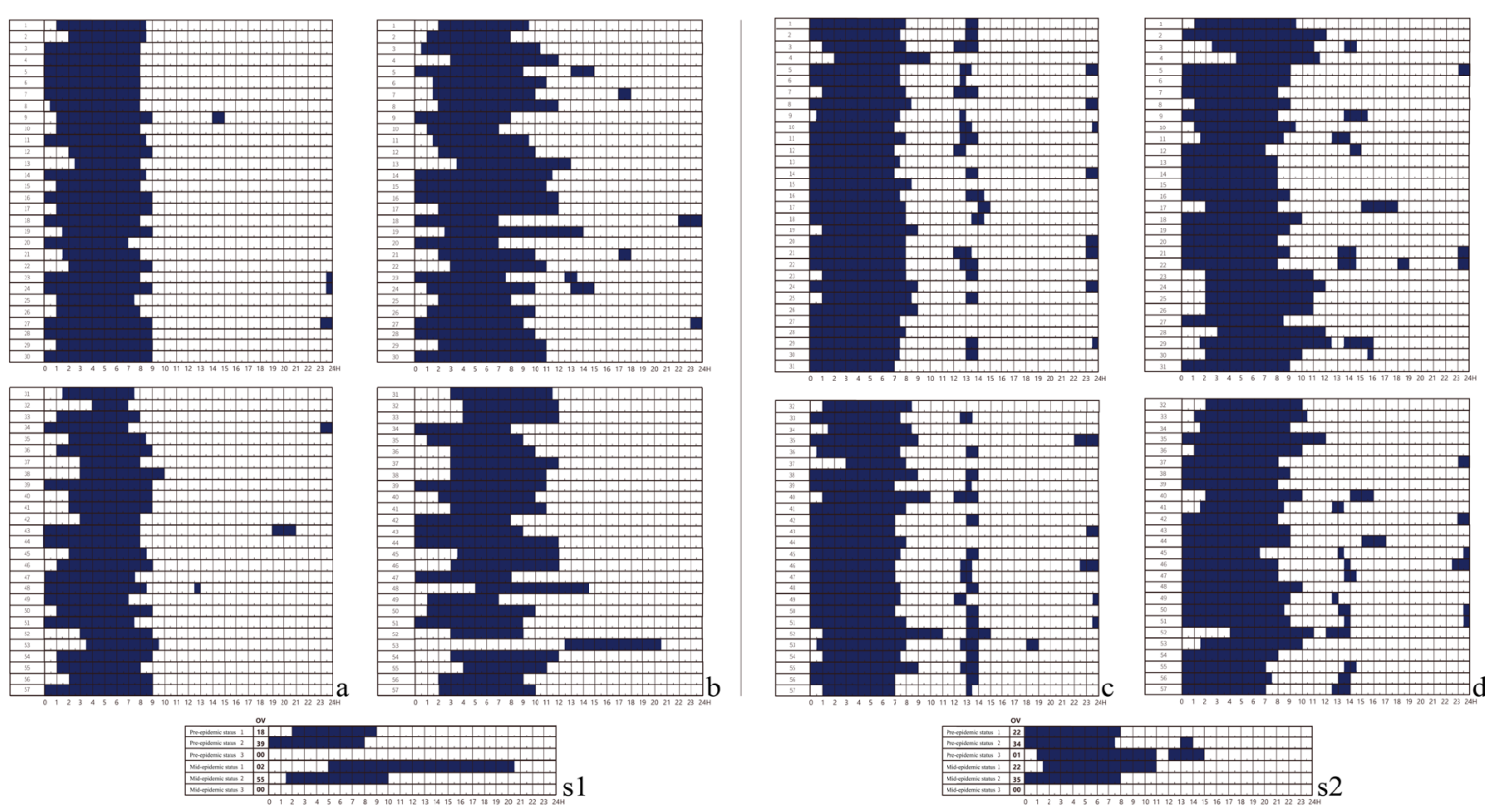

Figure 10: Sleeping ( $\mathrm{a} / \mathrm{b})$ Taiwan region; ( $\mathrm{b} / \mathrm{d})$ China region 

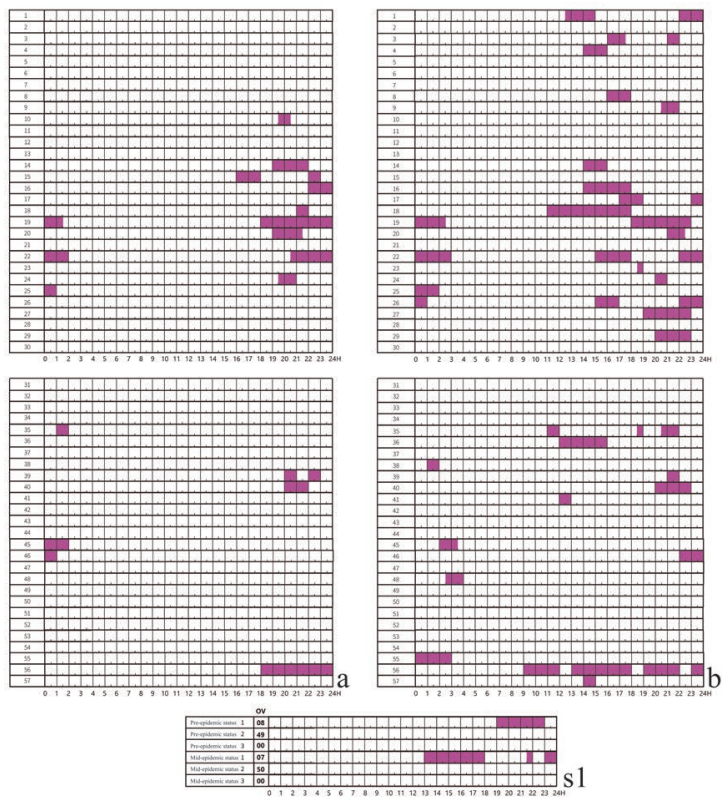
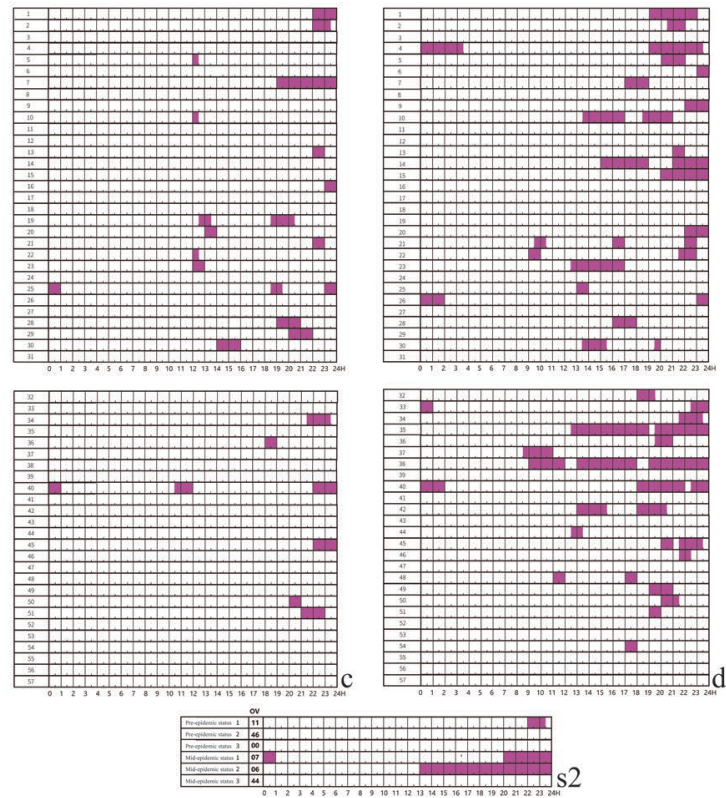

Figure 11: watching movies and TV (a/b) Taiwan region; (b/d) China region

In Taiwan: Before the epidemic, students generally stay up late in the evening. They would typically make phone calls, spend time on the internet, read or watch TV and movies, presenting an unhealthy lifestyle. During the epidemic, this unhealthy lifestyle was worsened. For lunch break, there was an hour's lunch break before the afternoon class before the epidemic, which was hardly enough for resting. Thus there was no such habit as noontime sleep. Activities such as watching movies and TV are the same as that of China.

In mainland China: Before the epidemic, students had a relatively regular lunch break on campus, and due to the arrangement of courses in the morning, they usually rested early in the evening; During the epidemic, students had to stay at home due to school shutdowns, bedtime and time of getting up were both postponed, resulting in delayed lunch break or skipping lunch break. The number of people watching movies and TV during the epidemic was significantly increased compared to before, and the average time spent was also increased.

Results analysis: Unhealthy sleep habits and long-time TV and movie watching during the epidemic is a factor that may cause the third state. During the epidemic, both regions presented the situation of late bedtime and late getting up, yet the sleep quality is not good enough, which is consistent with the survey results of the China Sleep Research Association, pointing out that the epidemic itself brings all kinds of information anxiety. People spend much time on their mobile phones at night. Besides, long-time coexistence in limited space increases the probability of friction and contradiction among some family members, which brought an even worse atmosphere for sleep. The epidemic highlights several important factors that usually affect sleep: anxiety, environment, mobile phones, and other technology products. Relevant studies have also confirmed that the lack of high-quality sleep will affect the adaptability during the epidemic period, and there are signs that the young generation is a highly vulnerable group to be influenced. People must maintain moderate exercise and a balanced diet and communicate with others to ease their troubles. The number of people watching TV and movies increased significantly during the epidemic, and the average time spent also increased. Although watching TV and movies is a positive way to deal with stress, spending too much time on it will reduce the time to communicate with family members, not to mention the harmful effects on the eyes, which will negatively affect the eyes dealing with stress. 


\subsubsection{Interpersonal relationship factor (Fig.12/Fig.13)}
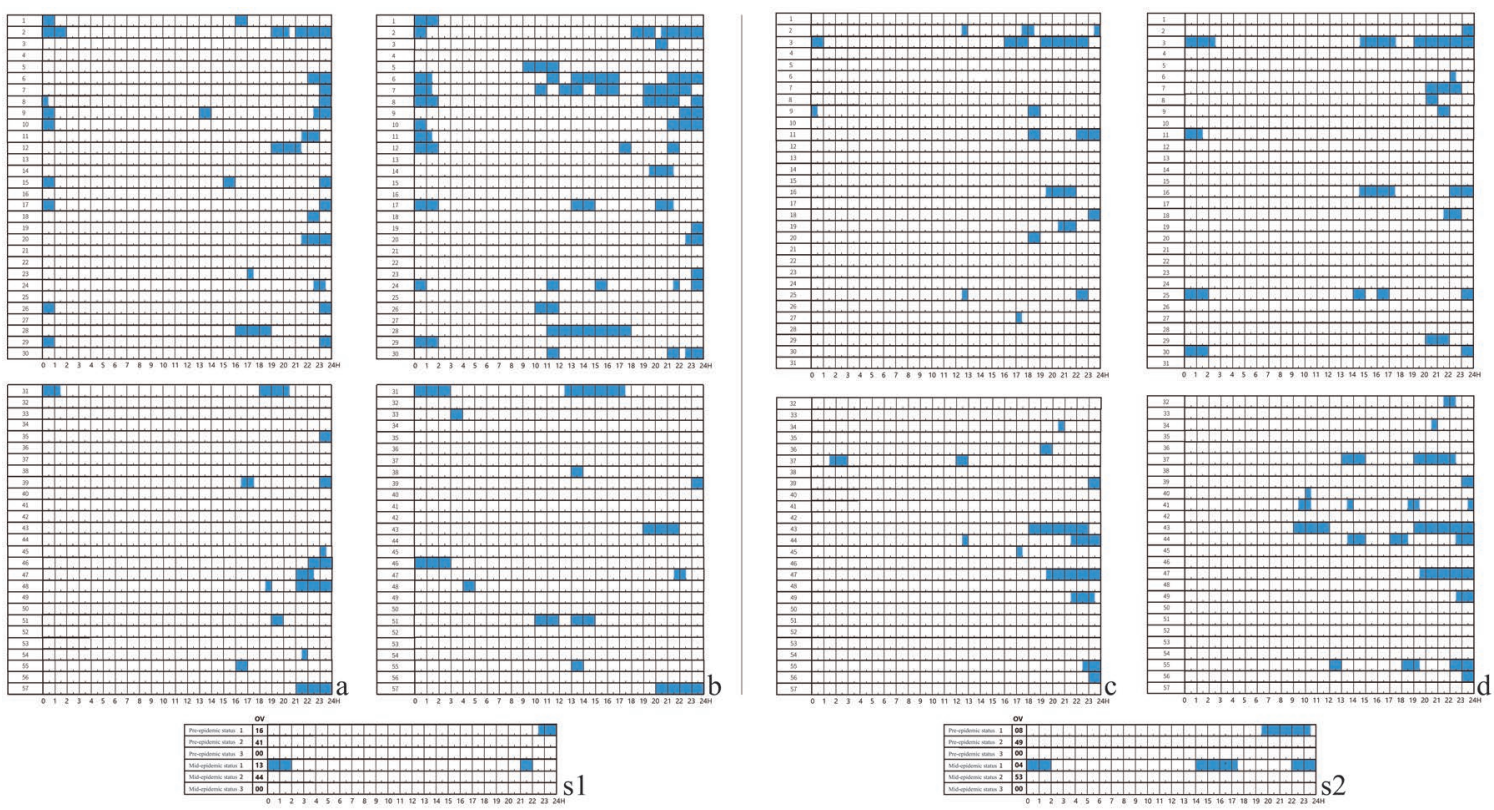

Figure 12: Calling Mail Internet Access ( $\mathrm{a} / \mathrm{b}$ ) Taiwan region; ( $\mathrm{b} / \mathrm{d})$ China region
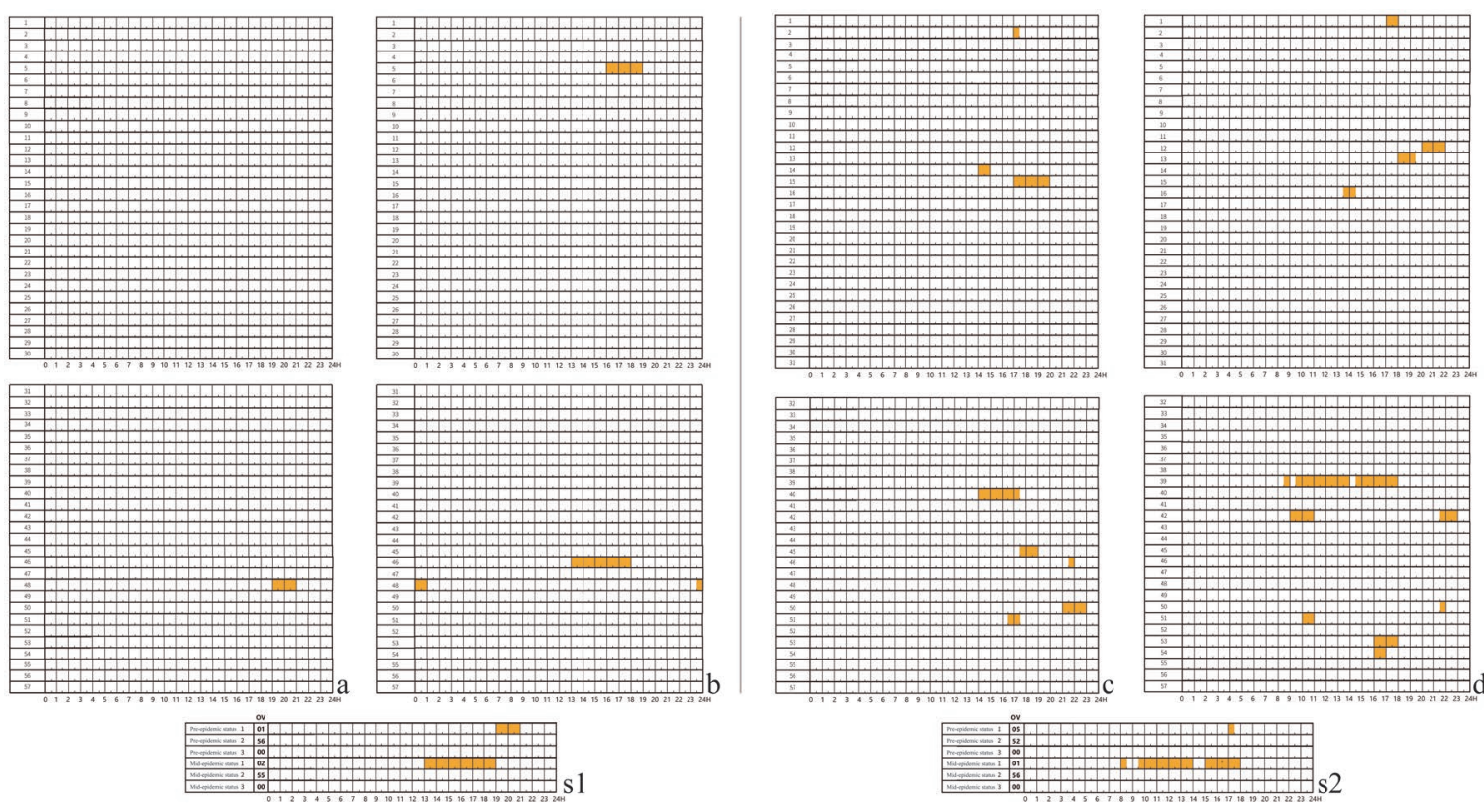

Figure 13: Activity Hours ( $a / b)$ Taiwan region; (b/d) China region

In Taiwan: Generally, the same as in mainland China.

In mainland China: During the epidemic, the number of people making phone calls and using the internet increased significantly; Activities increased compared with before; Activities such as dating and child care were rare both before and during the epidemic.

Results analysis: Virtual social interaction during the epidemic is a factor that may cause the third state. During the epidemic, the number of people of both regions using more internet functions such as phone and e-mail increased significantly, and the time spent also increased significantly. Due to the epidemic, in order to reduce the chance of contact with people, more students chose to communicate with people and complete their studies through the Internet. During the non-epidemic period, too much virtual social interaction will affect the regular social interaction, which will lead to the reduction of people's social circle, depression, and loneliness. 
However, after the outbreak of the epidemic, virtual social interaction helped to reduce contact with people, thus to reduce the risk of infection. On the whole, proper time management is needed to avoid the negative influence of virtual social interaction. The definition is much too broad, and more concrete information will be gathered in the follow-up interviews for a more detailed analysis.

\subsubsection{Health responsibility factor (Fig.14/Fig.15)}
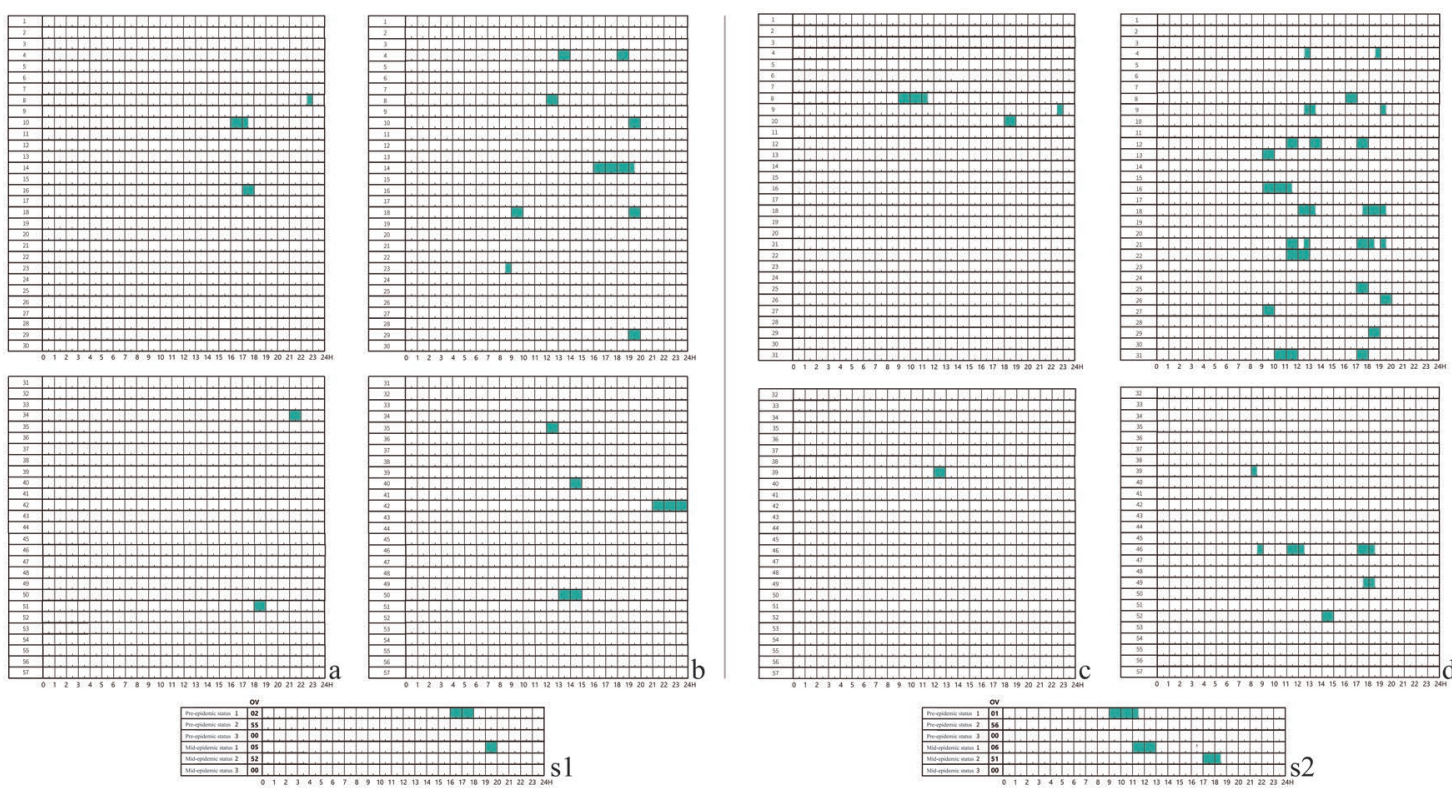

Figure 14: Homework
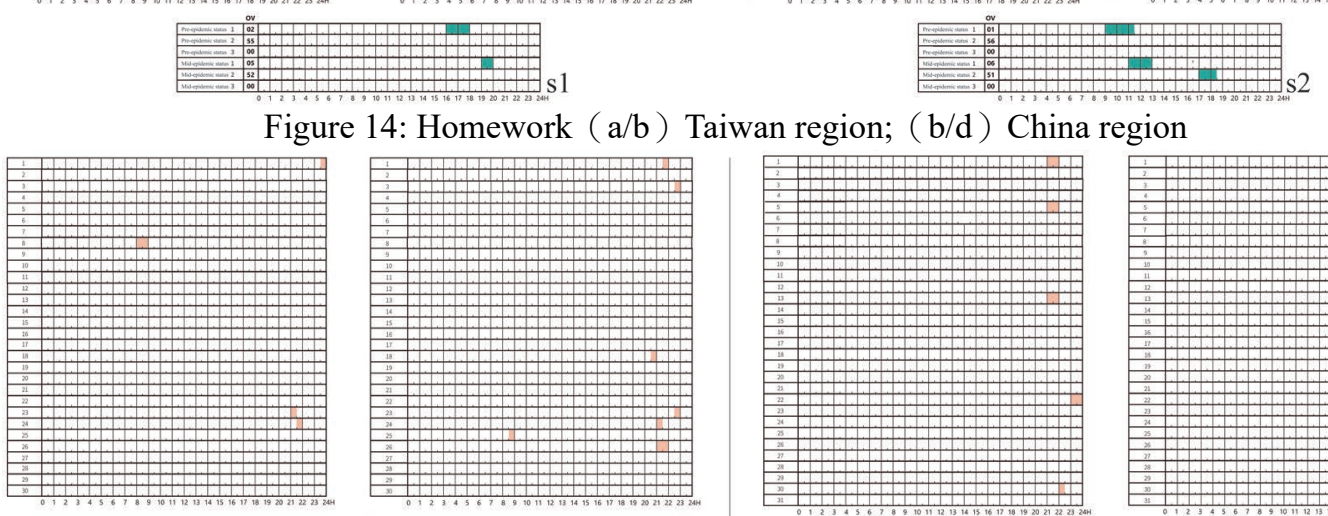

Taiwan region; ( $\mathrm{b} / \mathrm{d})$ China region
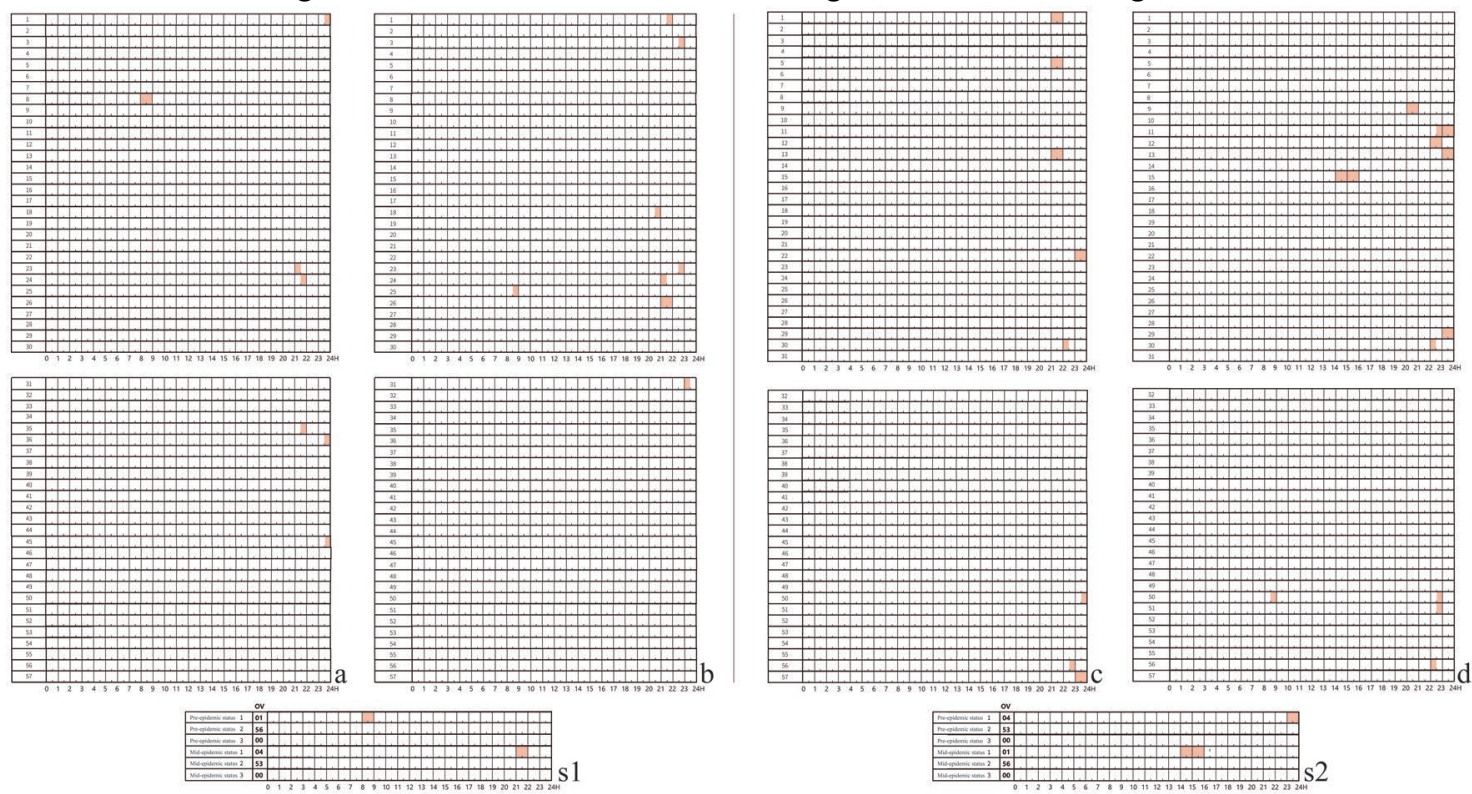

Figure 15: beauty care work ( $\mathrm{a} / \mathrm{b})$ Taiwan region; (b/d) China region

In Taiwan: Home quarantine was not required, so the people who would spend time on housework and beauty care increased, but not significantly as that of mainland China.

In China: Before the epidemic, doing housework (dormitory) at school was rarely seen. For the respondents, "housework" in school was merely a monthly routine - general cleaning. Staying at home during the epidemic made most of the people help to share some housework. In terms of gender, there was a significant difference between girls and boys for the time spent on housework, where girls were more willing to spend time. Also, during the epidemic, more people would spend more time on beauty care since there was enough time while staying at home. 
Results analysis: Housework and beauty care during the epidemic may alleviate the third state. Some studies have pointed out that doing housework is a good way to reduce stress. In doing housework, one can not only enjoy the fun of life but also ease the mood from the exercise and drive away from the pressure and trouble. The reasons include 1. a clean environment helps to relax the brain; 2. the increased amount of exercise helps promote metabolism; 3. it helps to improve living habits. Beauty care is a kind of performance to show the responsibility for one's own physical condition. Under the negative impact of the epidemic, more attention needs to be paid to people's health conditions to alleviate the epidemic's pressure and enhance the confidence to fight the virus.

\subsubsection{Spiritual growth (Fig. 16/Fig.17)}
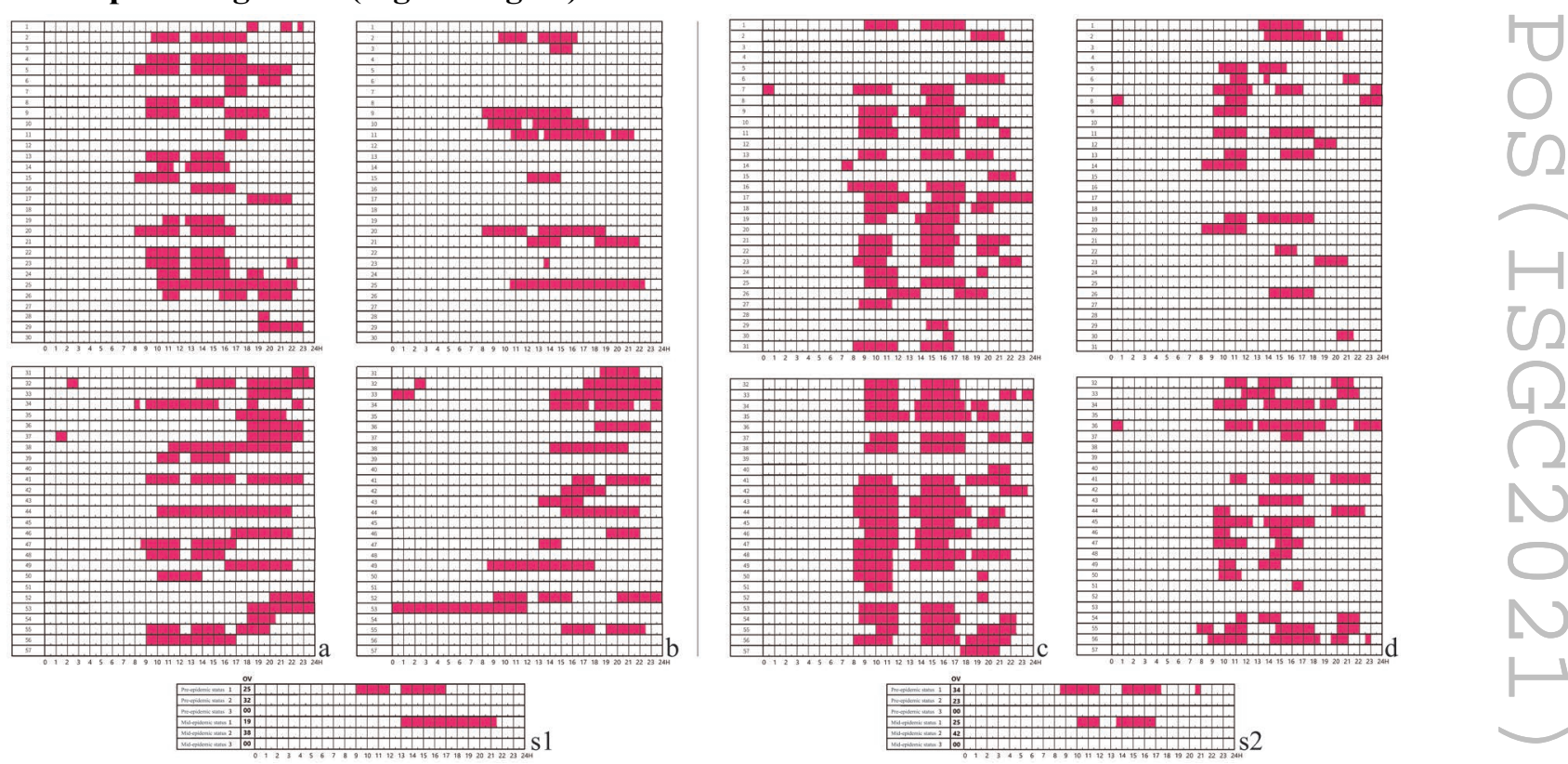

Figure 16: Work study schedule ( $\mathrm{a} / \mathrm{b}$ ) Taiwan region; (b/d) China region
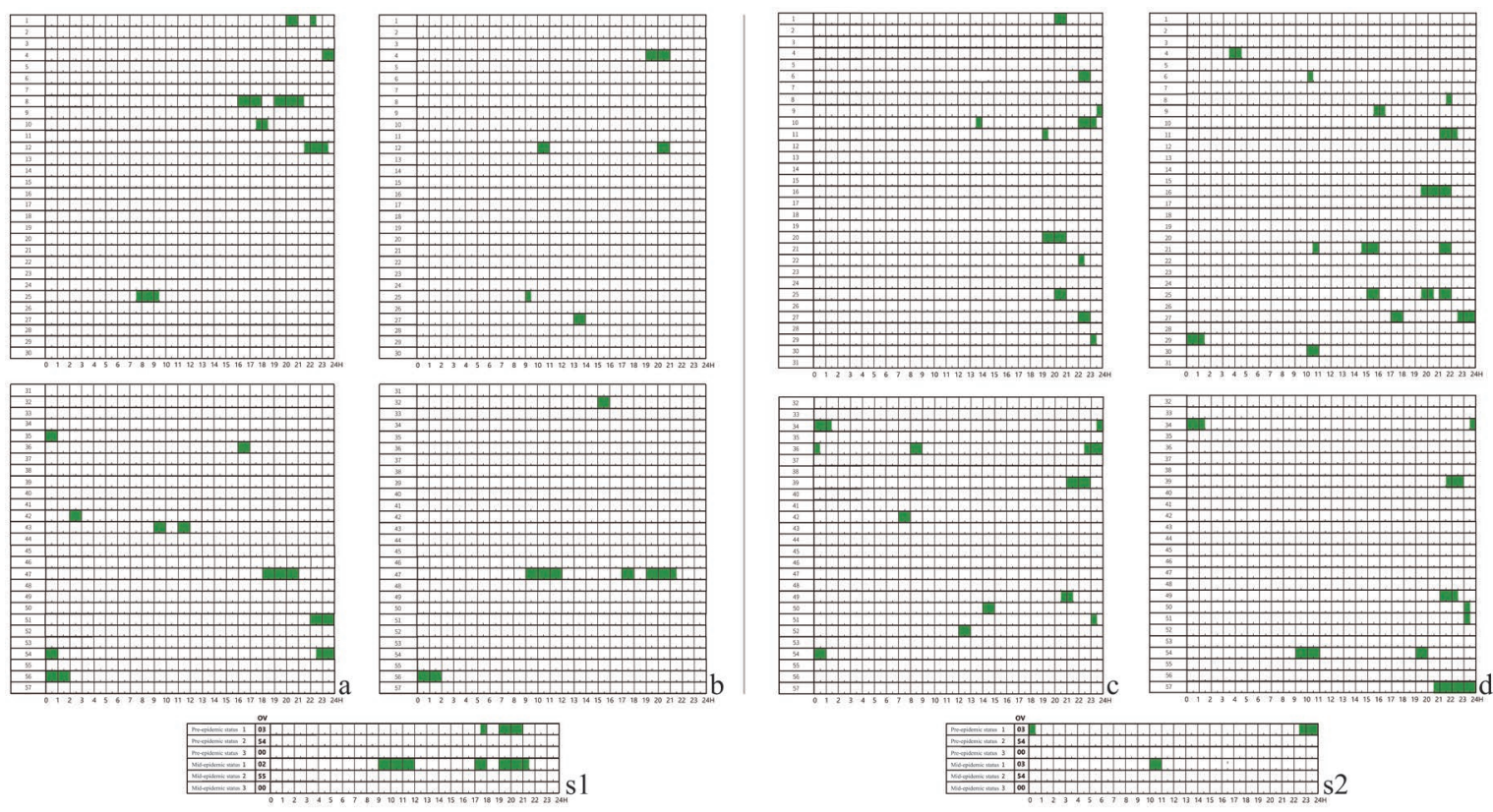

Figure 17: reading schedule ( $\mathrm{a} / \mathrm{b})$ Taiwan region; ( $\mathrm{b} / \mathrm{d})$ China region 
In Taiwan: Before the epidemic, the daily life schedule was relatively regular, which takes up most of the time during the day. During the epidemic, the overall trend is decreasing. According to the calculation results of SPPs, there is a difference of 1.7 hours between before and during the epidemic. During the epidemic situation, curriculum, commuting, reading, and rest time decreased in various degrees. Among them, reading does not require time at home, so more time would be spent on other activities while staying at home.

In mainland China: Before the epidemic, students mainly study in schools, while during the epidemic, they study at home independently. As shown in Figure 11, there is a regular work and study schedule before the epidemic, which mainly ranged between 8:00 a.m. to 5:00 p.m., and the study time in the evening is relatively scattered. During the epidemic, study activity was greatly reduced, the difference between before and during the epidemic was 2.7 hours, and the time was also scattered. During the epidemic, home quarantine reduced school activities and commuting to a great extent. However, the number and time of reading increased due to increased free time.

Results analysis: Study and work schedule during the epidemic may be a factor that causes the third state. Home quarantine leads to a lack of the constraints of curriculum hours and insufficient interaction with teachers and classmates, thus causes the decline of learning willingness and a negative impact on the will. The changes in the two regions before and during the epidemic are similar, which is study schedule was more regular before while the time and schedule were reduced and scattered. School shut down, and lack of constraint of school means the more independent study is required for the students. The overall learning time is relatively scattered reduced. Nevertheless, independent learning is affected by attitude and habits, including healthy living habits, time management skills, learning environment management, etc. Therefore, due to the epidemic situation, it is more necessary to cultivate the ability of independent study and selfmanagement. Reading can slow down the progress of the third state. Related studies have shown that reading can keep people away from depression, reduce anxiety and panic. So reading became important during the epidemic.

\section{Conclusion and Future Works}

Based on the above analysis, it can be concluded that: by analyzing the different life patterns between before and during the epidemic, combined with the six factors that may lead to the third state in the theory of health-promoting lifestyle, we can understand that when college students are faced with emergencies like the epidemic, the change of living environment may lead to the change of diet rules (skipping breakfast), which has a negative impact on nutrition. Physical exercise decreased and negatively affected sports and leisure factors in the areas with the serious epidemic situation. Sleeping time increased, but regular bedtime is disturbed by late sleep and late getting up, plus poor sleep quality and late sleep affect regular lunch break. Activities such as watching movies and TV increased significantly, both of which negatively affect stress management factors. Phone calls and internet activities affect interpersonal relationship factors, while suitable time spent online was favorable, and excessive time spent was negative. Time spent on housework and beauty care increased during the epidemic, which is positive health responsibility factor. School study activities decreased significantly due to the home quarantine, which negatively affected the spiritual growth factor. Increased time spent on reading during the epidemic was a positive factor.

Chen Jieyu's (2017) research on the influence factors of health-promoting lifestyle on the transformation of the third state for college students' health state are: spiritual growth, health responsibility, interpersonal relationship, stress management, nutrition, and sports leisure; This research is about in-school activities for college students, but this paper concentrates on the epidemic situation, so there are differences in terms of order. Based on the above analysis results, 
it is concluded that the order of these factors during the epidemic period is: spiritual growth, stress management, nutrition, sports and leisure, interpersonal relationship, and health responsibility. Therefore, college students need to pay more attention to their mental changes facing sudden situations. Moreover, in the face of the pressure caused by the epidemic, they need to be guided to take appropriate measures to reduce stress and maintain adequate and regular sleep. At the same time, maintaining regular diet and exercise habits are also important. Keep in touch with friends and family members through the Internet. Share more family affairs and pay attention to personal health condition to improve health awareness, and to actively face the negative impact of the epidemic. In the follow-up research, by way of interview, a more in-depth understanding of the young generation's views on the factors that may lead to the third state will be reached. A more improved plan will be put forward through the service design method in order to improve young generation's health awareness to cope with the similar epidemic situation in the future.

\section{Reference}

[1] Feng, Y., et al., Associations of living environment and lifestyle factors with sub-health status: A population-based cross-sectional study in urban China. 2020.

[2] Bi, J., et al., Association of lifestyle factors and suboptimal health status: a cross-sectional study of Chinese students. BMJ open, 2014. 4(6).

[3] Ma, C., et al., Association between lifestyle factors and suboptimal health status among Chinese college freshmen: a cross-sectional study. BMC public health, 2018. 18(1): p. 1-9.

[4] Xu, T., G. Zhu, and S. Han, Prevalence of suboptimal health status and the relationships between suboptimal health status and lifestyle factors among Chinese adults using a multi-level generalized estimating equation model. International journal of environmental research and public health, 2020. 17(3): p. 763 .

[5] Pan, Y., et al., Sub-Health Status Survey and Influential Factor Analysis in Chinese during Coronavirus Disease 2019 Pandemic. Journal of Korean Academy of Nursing, 2021. 51(1): p. 5-14.

[6] Chang, J., Y. Yuan, and D. Wang, [Mental health status and its influencing factors among college students during the epidemic of COVID-19]. Nan Fang Yi Ke Da Xue Xue Bao, 2020. 40(2): p. 171176.

[7] Larsson, S.C., J. Kaluza, and A. Wolk, Combined impact of healthy lifestyle factors on lifespan: two prospective cohorts. Journal of internal medicine, 2017. 282(3): p. 209-219.

[8] Yang, Chia-Ju, A study of health promotion lifestyle and its related factors among university students. Yi-Shou University, Department of Nursing Dissertation, 2018: p. 1-81.

[9] Xue, Y., et al., Association analysis of Suboptimal health Status: a cross-sectional study in China. PeerJ, 2020. 8: p. e10508.

[10] Ma, C., et al., Association between lifestyle factors and suboptimal health status among Chinese college freshmen: a cross-sectional study. BMC Public Health, 2018. 18(1): p. 105.

[11] Kumari, A., et al., A short questionnaire to assess changes in lifestyle-related behaviour during COVID 19 pandemic. Diabetes \& Metabolic Syndrome: Clinical Research \& Reviews, 2020. 14(6): p. 1697-1701. 
[12] Chen, J.Y., et al., Effect of health-promoting lifestyle on the transformation of subhealth status. Journal of Southern Medical University, 2017. 37(2): p. 184.

[13] Lee, R. H., Introduction to Smart and Healthy Living. 2020.

[14] Ching-Rong Huang and Vámonos vámonos, Exploring the influence of the Big Five personality traits and health cognitions on health behaviors among college students. Journal of Health Promotion and Health Education, 2016.

[15] Chen, Min-Lang and Yen, Jia-Ying, A study on the factors related to college students' self-awareness of health, health cognition and eating behavior in four universities in central Taiwan. Hong Kong Journal of Science, 2015(76): p. 111-122.

[16] Chang, K.H., Yuan, Y.X., and Wang, D. Analysis of the mental health status and influencing factors of college students under the novel coronavirus pneumonia epidemic. Journal of Southern Medical University, 2020. 40(2): p. 171. 